\title{
ANÁLISIS DEL CONSUMO DE AGUA POTABLE EN EL CENTRO POBLADO DE SALCEDO, PUNO
}

\section{Samuel Huaquisto Cáceres y Isabel Griscelda Chambilla Flores}

\section{RESUMEN}

El aumento de la densidad poblacional y la dinámica de la expansión urbana hacen que estas zonas sean vulnerables a la dotación de agua potable por la creciente demanda y los complejos sistemas de tratamiento y abastecimiento. El estudio analiza el consumo de agua influenciado por el ingreso económico y número de habitantes por vivienda a fin de compararlos con los valores recomendados por la OMS; además, se determina la variación diaria y horaria del consumo de agua en la zona urbana de Salcedo-Puno. La muestra para el análisis del consumo de agua fue de 1246 viviendas y para las variaciones diarias y horarias 39 viviendas, cuyos datos de consumo y variación fueron recopilados de la Empresa Prestadora del Servicio y de observaciones in situ respectivamente. Se determinó que el consumo promedio de agua fue de $67 \mathrm{l} / \mathrm{hab} / \mathrm{d}$ influenciados por factores como ingreso económico, número de habitantes por vivienda y meses del año. Los coeficientes de variación diaria y horaria que inciden en el diseño de la captación, conducción y reservorio, así como para la aducción y red de distribución fueron $\mathrm{K}_{1}=1.33$ y $\mathrm{K}_{2}=3.80$ respectivamente, siendo este último superior a los recomendados por los reglamentos debido a la no continuidad del servicio en el lugar. En conclusión, los valores del consumo de agua potable están por debajo de los niveles establecidos por la OMS de $100 \mathrm{l} / \mathrm{hab} / \mathrm{d}$, en el inciden entre otros factores el ingreso económico y el número de habitantes por vivienda, siendo el consumo máximo de 72,83 l/hab/d para viviendas con 5 habitantes y mínimo de 50,55 l/hab/d para viviendas de 12 habitantes.

Palabras Clave: Agua Potable, Análisis, Dotación, Variación Diaria, Variación Horaria.

DOI: 10.23881/idupbo.019.1-9i 